\title{
Relevance of Chest CT Scan Requests in Two University Teaching Hospitals in a Developing Country
}

\author{
Armel Philippe Awana ${ }^{1,2 *}$, Ambroise Merci Seme Engoumou ${ }^{3}$, Julienne Onguene Medza4, \\ Patrice Esame Ndive², Odile Fernande Zeh ${ }^{2,4}$, Pierre Ongolo Zogo ${ }^{2,5}$, Samuel Nko'o Amvene ${ }^{2,6}$ \\ ${ }^{1}$ Yaounde Jamot Hospital, Yaounde, Cameroon \\ ${ }^{2}$ Faculty of Medicine and Biomedical Sciences, University of Yaounde I, Yaounde, Cameroon \\ ${ }^{3}$ Vitro Fertilisation Yaounde Gynaecological Endoscopic Surgery and Human Reproductive Teaching Hospital, Yaounde, Cameroon \\ ${ }^{4}$ Yaounde Gynaecology Obstetrics and Pediatrics Hospital, Yaounde, Cameroon \\ ${ }^{5}$ Yaounde Central Hospital, Yaounde, Cameroon \\ ${ }^{6}$ Yaounde University Teaching Hospital Centre, Yaounde, Cameroon \\ Email: *armelawana@yahoo.fr
}

How to cite this paper: Awana, A.P., Engoumou, A.M.S., Medza, J.O., Ndive, P.E., Zeh, O.F., Zogo, P.O. and Amvene, S.N. (2018) Relevance of Chest CT Scan Requests in Two University Teaching Hospitals in a Developing Country. Open Journal of Radiology, 8, 84-90.

https://doi.org/10.4236/ojrad.2018.82010

Received: April 16, 2018

Accepted: June 22, 2018

Published: June 26, 2018

Copyright $\odot 2018$ by authors and Scientific Research Publishing Inc. This work is licensed under the Creative Commons Attribution International License (CC BY 4.0).

http://creativecommons.org/licenses/by/4.0/

\section{(c) (i) Open Access}

\begin{abstract}
Chest investigation is common in hospital practice. Chest X-ray is readily available and usually the first chest investigation. Thoracic CT scan constitutes an alternative and complimentary chest investigation. It is currently the most efficient investigation for the chest and its contents. Objectives: To evaluate the relevance of chest CT Scan requests in two university teaching hospitals in Cameroon. Material and Methods: We conducted a cross-sectional, retrospective and descriptive study at the Radiology and imaging units of the Yaounde Central Hospital and the Yaounde University Teaching Hospital Centre. Included in our study were files of patients who had a chest CT scan investigation during three years. Results: We had a study population of 323 subjects. The age interval was 23 months to 91 years old. Pulmonologist were the most prescribers with $27.2 \%$. We had $80 \%$ conformity of indications with French Society of Radiology (FSR) standards. 50 over of 323 indications were not recommended by the FSR. Conclusion: There is a conformity rate of $80 \%$ between indications and the FSR recommendations.
\end{abstract}

\section{Keywords}

CT Scan, Chest, Relevance, Request, Prescribers

\section{Introduction}

Chest investigation is common in hospital practice. Chest X-ray is readily avail- 
able and usually the first chest investigation. The method of realisation of the chest X-ray however, limits it to the diagnosis of certain pathologies [1].

Thoracic CT scan constitutes an alternative and complimentary chest investigation. It is currently the most efficient investigation for the chest and its contents [2]. In Canada, Turner concludes that Chest CT scan shows new elements in 56\% for diagnosis in 2006 [3]. The benefits of this CT scan can lead to bad use of this exam.

The French National Authority for Health (F.N.A.H), the French Society of Radiology (FSR) and the French society of biophysics and Nuclear Medicine recommend good use of morphologic investigations. To this effect, a guide for good use of radiological investigations was edited with precise indications for thoracic CT scan [4]. Monkam in 1996, 8 years after the first scan in Cameroon, gave the profile of chest pathologies exams in General Hospital of Yaounde [5].

Considering the increase in the number of scanners in health facilities in Cameroon, we decided to evaluate the relevance of chest $\mathrm{CT}$ scan requests in two university teaching hospitals in Cameroon.

\section{Methods}

\subsection{Type of Study}

We conducted a cross-sectional, retrospective and descriptive study at the Radiology and imaging units of the Yaounde Central Hospital and the Yaounde University Teaching Hospital Centre.

Included in our study were files of patients who had a chest CT scan investigation from 2006 to 2009 . We excluded all incomplete files.

\subsection{Data Analysis}

Parameters collected were; epidemiological profile of patients, indications for the investigation, the prescriber's speciality and the results. Our results were compared to the guide for good use of radiological investigations of the French National Authority for Health (F.N.A.H).

\subsection{Statistical Method}

A chi-square test was used to compare qualitatives files between the correlation of a conclusion and indication by speciality.

\section{Results}

\subsection{Sociodemographic Characteristics}

We had a study population of 323 subjects. The age interval was 23 months to 91 years old. The mean age was 46.6 years \pm 20 years.

\subsection{Distribution of Patients According to Sex and Age}

The most represented age ranges were 31 - 40 years and 41 - 50 years. The male sex was the most represented (Figure 1). 


\subsection{Prescriber Profile}

Table 1 presentes the profile of prescribers. Pneumology was the most represented speciality followed by general medicine at $27.2 \%$ and $18.6 \%$ respectively. We note that radiologist were 10 .

\subsection{Distribution of Indication within Pathologies Groups}

Table 2 representes the distribution of indication by group. The primary indication was suspicion of tumoral lesions (44.9\%), followed by lung parenchyma pathologies. There is no indication in 5.3\%.

\subsection{Conformity of Indications According to the French Society of Radiology Standards}

Indications for Chest imaging were confronted to the French Society of Radiology recommendations. The Figure 2 represents the conformity of indication to the FSR recommendation. The conformity criteria was that the indication should be recommended by the FSR. We had $80 \%$ conformity of indications.

\subsection{Inconsistent Indications}

Table 3 shows the principal inconstant indications in our study. 50 of 323 indications were not recommended by the FSR. The thoracic pain was the main inconsistent indication followed by pneumonia.

\subsection{Global Coherence between Indications and CT Scan Results}

There was an overall accuracy of $63 \%$ between the indications and results of Chest CT scans (Figure 3). In 5\% we can not evaluate the accuracy because there is no indication in request of chest scan.

\subsection{Coherence of Indications and CT Scan Results According to Specialty}

The correlation between the clinical exam and CT scan results varied according to different specialties. Table 4 represents the coherence of indications and results according to speciality. There was a statistically significant difference among prescribers $(\mathrm{p}=0.001)$.

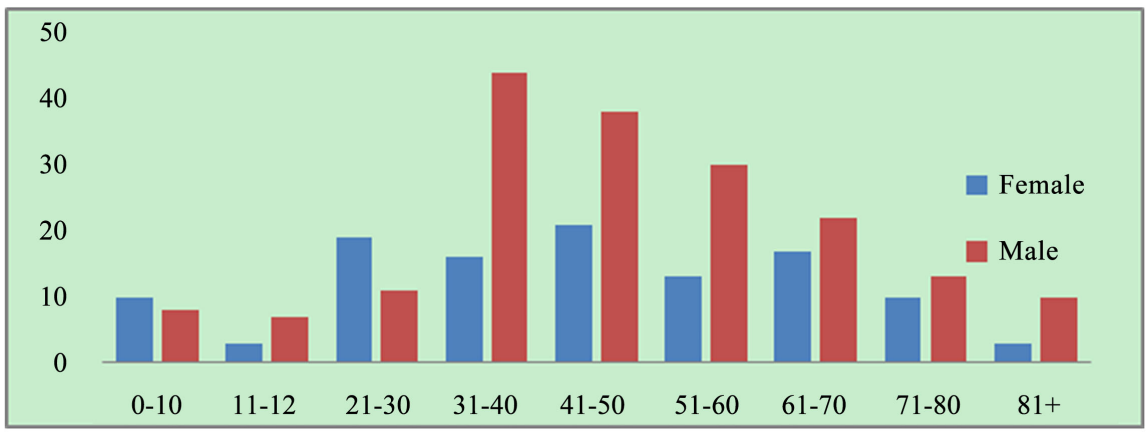

Figure 1. Distribution of patients according to sex and age. 


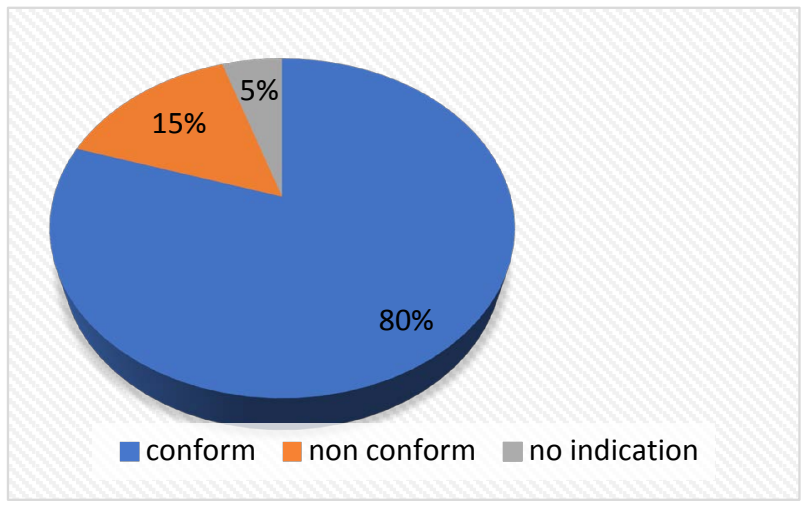

Figure 2. Conformity of indications to FSR recmmandation.

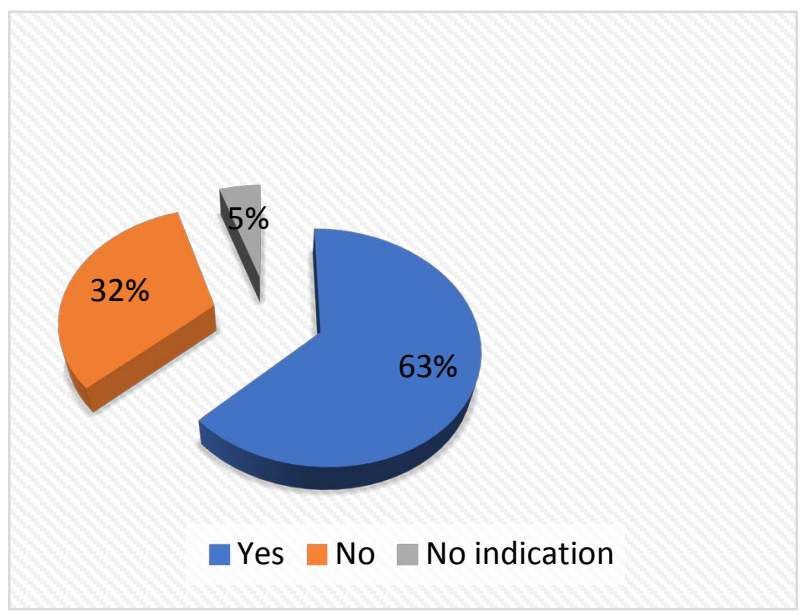

Figure 3. Percentage of overall accuracy.

Table 1. Prescriber profile.

\begin{tabular}{ccc}
\hline Spéciality & Frequency & Percentage \% \\
\hline Pulmonologist & 88 & 27.2 \\
General practitioner & 60 & 18.6 \\
Surgeon & 38 & 11.7 \\
Others & 37 & 11.4 \\
Cardiologist & 23 & 7.1 \\
Anesthetist & 19 & 5.9 \\
Internist & 15 & 4.6 \\
Gastro enterologist & 12 & 3.7 \\
Pediatrician & 11 & 3.4 \\
Radiologist & 10 & 3.1 \\
Rheumatologist & 6 & 1.9 \\
Otolaryngologists & 2 & 0.6 \\
Oncologist & 1 & 0.3 \\
Hematologist & 1 & 0.3 \\
TOTAL & 323 & 100 \\
\hline
\end{tabular}


Table 2. Distribution of indications by group.

\begin{tabular}{ccc}
\hline Group & Frequency & Percentage (\%) \\
\hline Tumoral pathology & 145 & 44.9 \\
Parenchymatous pathology & 47 & 14.5 \\
Vascular pathology & 22 & 6.8 \\
Traumatology & 19 & 5.9 \\
None indication & 17 & 5.3 \\
Pleural pathology & 16 & 4.9 \\
Others & 57 & 17.6 \\
TOTAL & 323 & 100
\end{tabular}

Table 3. Inconsistent indications for chest CT scan.

\begin{tabular}{cc}
\hline Clinical indication & Frequency \\
\hline Thoracic pain & 17 \\
Pneumonia & 15 \\
Tuberculosis & 5 \\
Dyspnea & 5 \\
Check up & 3 \\
Cardiac pathologies & 3 \\
Cyphoscoliosis & 1 \\
Syncopa & 1 \\
TOTAL & 50
\end{tabular}

Table 4. Coherence according to speciality.

\begin{tabular}{ccccc}
\hline Speciality & Discordant & Concordant & Total & \% concordance \\
\hline Rheumatologist & 0 & 6 & 6 & 100.0 \\
Internist & 1 & 13 & 14 & 92.9 \\
Pulmonologist & 22 & 63 & 85 & 74.1 \\
Pediatrician & 3 & 8 & 11 & 72.7 \\
Surgeon & 12 & 25 & 37 & 67.6 \\
Cardiologist & 7 & 14 & 21 & 66.6 \\
General practionner & 21 & 36 & 57 & 63.2 \\
Others & 13 & 19 & 32 & 59.4 \\
Anesthetist & 8 & 10 & 18 & 55.6 \\
Radiologist & 5 & 4 & 9 & 44.4 \\
Gastro Enterologist & 9 & 3 & 12 & 25.0 \\
\hline
\end{tabular}

$\mathrm{P}=0.001$ CHI 2 . 


\section{Discussion}

\subsection{Study Population}

The mean age of our study population is comparable to those of Ngoka et al. at Bamako (40.5 years) and Monkam et al. in Yaounde (41.8 years) [5] [6]. Also, the age ranges were similar to those found in litterature [5] [6] [7].

This can be explained by the fact that, most chest diseases especially tumors, are frequent at this age [5] [6].

\subsection{Profile of Chest CT Scan Prescribers}

Pulmonologist were the main chest CT scan prescribers in our study. Turner et al. in Canada had 70\% of pneumologists as prescribers in 2006 [3]. This can be explained by the fact that, most chest diseases are pneumology related. Most prescriptions of this study came from the Yaounde Jamot Hospital which is a reference centre in pneumology in Cameroon.

\subsection{Indications of Chest CT Scan}

There was a good knowledge by prescribers of indications coherent with FSR, as $80 \%$ of indications were coherent. This could be explained by the fact that the most represented speciality was pneumology.

\subsection{Tumoral Pathologies}

Our results are superior to that found by Monkam who found that tumor pathology accounted for $33.8 \%$ of applications instead of $44.9 \%$ in our study [4]. Indeed the search for tumor pathology supplanted the other clinical presomptions in this work. This confirms the importance of the thoracic CT scan in screening, localization, search for extension of tumors [1].

We found that in the tumoral pathology, the primary tumor balance was more solicited than the search for metastases. This confirmed the finding of Ngoka et al. who noted that in thoracic pathology, the indications were more tumor-oriented than extensional [6].

\subsection{Inconsistent Indications}

According to FSR, tuberculosis and pneumonia are not recommended indications for a Chest CT scan. Lone Chest pain was the main non coherent indication in our series. This cannot be an indication without a chest $\mathrm{X}$ ray previously done. The Chest $\mathrm{x}$ ray remains the first exam of investigations of chest pathologies.

Germanaud et al. in 2010, found out that 5.5\% of indications were not coherent [8].

$5 \%$ of requests did not have a clinical indication in our study. This is less than what was found by Roussel et al. in 2002 [9]. The execution of a particular imaging technique, especially a Chest CT scan depends on the indication. 


\subsection{Coherence According to Speciality}

Pulmonologists have a 74\% coherence despite de great number of requests. This can be explained by the fact that they are specialised in chest diseases. They also know indications and aims of exams.

\section{Conclusions}

At the end of this study, we can conclude that:

- Pulmonologists have the highest request rate for Chest CT scan with high coherence rate between indications and results (74\%).

- There is a conformity rate of $80 \%$ between indications and the FSR recommendations.

- The main non coherent indication for chest CT scan was chest pain (17/50).

\section{Limitation of Study}

The main limitation of our study was that it was retrospective study.

\section{Conflicts of Interest}

The authors declare they have no conflict of interest.

\section{References}

[1] Haute Autorité de la Santé (2009) Principales “non-indications" de la radiographie du thorax. 1-18.

[2] Lacrosniere, L., Nores, J., Bergal, S., et al. (1995) Le scanner en pathologie thoracique. La Presse Médicale, 24, 812-821.

[3] Turner, M., Mayo, J., Müller, N., et al. (2006) Computed Tomography Scans of Thorax. Canadian Respiratory Journal, 13, 311-316. https://doi.org/10.1155/2006/859870

[4] Société Française de Radiologie (2005) Guide de bon usage des examens d'imagerie médicale. 46-50.

[5] Monkam, S.E. (1996) Profil de la pathologie thoracique à l'HGY. Th D Méd, Yaoundé.

[6] Ngoka, T.F. (2003) Bilan de 5 années d'activité du scanner XVID TOSHIBA à l’hôpital du Point G de 1999 à 2003. Th D Méd, Bamako.

[7] Ranaivoarison, C. and Seka, R. (1994) Bilan de l'activité scanographique au centre intégré de diagnostic et soins intensifs (C.I.D.S.I) de Treichville, Cote d'Ivoire. Abidjan.

[8] Germanaud, J., Destembert, B., Brisacier, P., Schmitt, B. and Charlon, R. (2000) Évaluation de la qualité des comptes rendus en imagerie médicale. Revue Medicale Assurance Maladie, 3, 41-45.

[9] Roussel, N. and Lelièvre, P. (2002) Améliorer la qualité des prescriptions d'examens d'imagerie médicale. Journal de Radiologie, 83, 621-625. 